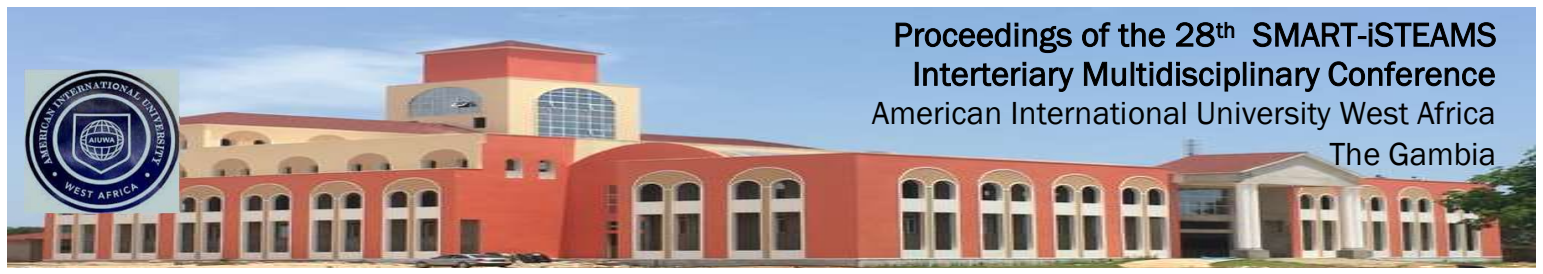

Full Research Paper

\title{
Potential Human Hair and Sheep Wool Dyeing Characteristics of Hair Colour Formulations Prepared from Four Vegetable Dyes.
}

Oyedeji, Folashade 0. Momoh, Joshua 0.

Department of Chemistry University of Ibadan Ibadan, Nigeria

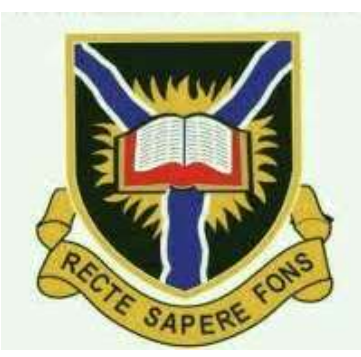

E-mails omoeage2002@yahoo.com

Phones

$+2348033946729$

\section{ABSTRACT}

Man insatiable desires often leads him to many choices. Some functional, others for the purpose of decoration or acceptability. The dyeing of hair can be comfortably placed in any of the three categories. The production of hair colours is a multi-billion dollar industry that involves the use of both plant-derived and synthetic dyes. Unlike synthetic dyes which can be toxic and harmful to the environment; natural dyes are biodegradable, non-toxic and compatible with environment. In the present study the comparative black - brown colouring effect of seven dye formulations made from ethanol and chloroform extracted pigments of some local dye yielding plants; Lawsonia inermis, Loncocarpus cyanescens, Pterocarpus osun and Trema orientalis on grey human hair and sheep wool was observed and recorded after two hours of dye uptake; storage at room temperature for 4 days and exposure to sunlight for 4 days. \% yield of extracted dye ranged from 1.04 - 3.20 in the order Lawsonia inermis < Trema orientalis < Lonchocarpus cyanescens < Pterocarpus osun dye. The colours of the dyes obtained were orange (Lawsonia inermis), yellow (Loncocarpus cyanescens), dark red (Pterocarpus osun) and dark green (Trema orientalis). The human hair took up the dye more readily than the sheep wool and the black-brown colouring effect was maximum with formulation 7 and in the order PF $7>\mathrm{PF} 3>\mathrm{PF} 5>\mathrm{PF} 4>\mathrm{PF} 1>\mathrm{PF}$ $6>\mathrm{P} 2$ with the colour being retained for the greatest period of time at room temperature while fading gradually with the length of exposure to sunlight for both human hair and wool. The colour deepened however for sheep wool, with length of stay at room temperature. In conclusion, the natural dye formulations coloured the hair better than sheep wool, it may therefore be suitable for the formulation of hair colouring solution, after toxicity tests, colour fixing and modification studies have been carried out on the dyes.

Keywords: Lawsonia inermis, Loncocarpus cyanescens, Pterocarpus osun, Trema orientalis, Human hair, Sheep wool, Vegetable dyes.

Proceedings Reference Format

Oyedeji, F.O. \& Momoh, J.O. (2021): Potential Human Hair and Sheep Wool Dyeing Characteristics of Hair Colour Formulations Prepared from Four Vegetable Dyes. Proceedings of the 28th iSTEAMS Intertertiary Multidisciplinary Conference. American International University West Africa, The Gambia. October, 2021. Pp143-156 www.isteams.net/gambia2021.

DOI - https://doi.org/ 10.22624/AIMS/iSTEAMS-2021/V28N2P11 


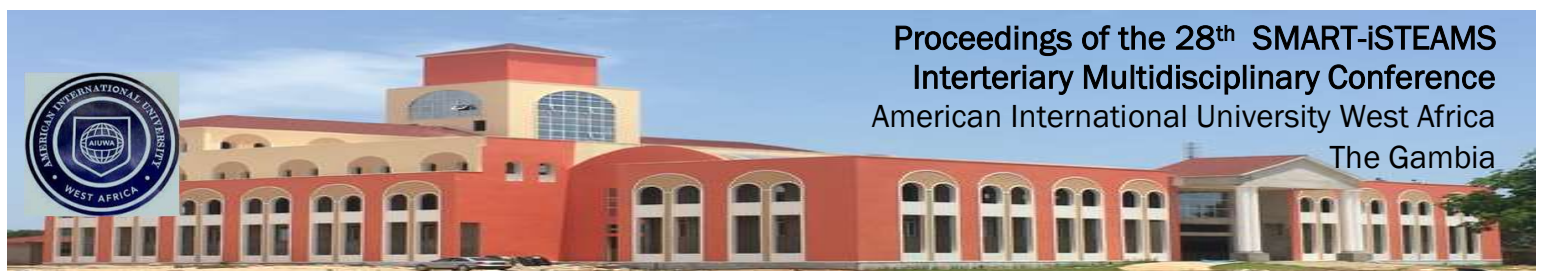

\section{INTRODUCTION}

A dye is a coloured substance that chemically bonds to the substrate to which it is being applied. It is usually applied from an aqueous solution and may require a mordant to improve the fastness of the dye on the fiber (Booth et. al., 2000). Dyes may be classified according to their solubility or chemical properties. Therefore, there are acidic, basic, direct, mordant, vat, reactive, disperse and sulphur dyes. Dyes can also be synthetic or of natural origin. Synthetic dyes are manmade from resources such as petroleum by-products and earth minerals (Zollinger, 2003). Natural dyes are dyes derived from vegetable sources such as roots, berries, barks, leaves, wood, fungi and lichens (Kvavadze et. al., 2009).

Hair is one of the most distinctive elements of human appearance. The natural colour of hair commonly reflects an individual's geographic or ethnic origin (Corbelt, 1998). The colour of hair is due to the presence of pigments (melanin) stored in the cortex of hair. Eumelanin, the black pigment is responsible for hair shades from black to brown and phaeomelanin, the lighter pigment is responsible for red and yellowish colours. Hair with no melanin pigment on the cortex is completely white and with few pigments provides grey colour (Sharma, 2008). Dissatisfaction with the colour of hair has led to the application of various types of natural and synthetic substances on hair. The use of cosmetics in order to change hair colour, such as hair dye products, occurs with high frequency, mostly among the female population (Harrison and Sinclair, 2003).

Hair colour is one of the oldest, well known cosmetics that have been used by many ancient cultures in different parts of the world (Shahi et. al., 2017). Hair colouring, is mainly for the practice of cosmetic; for example, to cover grey hair, to change to a colour regarded as more fashionable or desirable or to restore the original hair colour after it has been discoloured by hair dressing processes or bleaching. There are different types of hair colours, permanent, demipermanent semi-permanent and temporary (Boga et. al., 2013). Permanent hair colours contain ammonia and must be mixed with a developer or oxidizing agent in order to permanently change hair colour.

Demi-permanent colour that contains an alkaline agent other than ammonia e.g ethanolamine, sodium carbonate and soon. Semi-permanent hair colour has smaller molecules than temporary dyes, these dyes only partially penetrate the hair shaft, they contain none or very low levels of developer, peroxide or ammonia. Temporary hair colour is available in various forms, it is typically brighter and more vibrant than semi-permanent. The pigment particles are large and cannot penetrate the cuticle layer (Da Franca et. al., 2015). The particles remain adsorbed to the hair shaft and are easily removed with a single shampooing.

According to the international agency for Research on Cancer (IARC), in vitro and in vivo studies (in exposed human population) have shown that some hair dyes and many chemicals used in the hair dyeing process can be considered mutagenic and carcinogenic (Gera et.al., 2018). The global scenario is now changing towards the use of safer, non-toxic and natural products with traditional use (Zaid et. al., 2013). Vegetable dyes are semi-permanent dyes, used traditionally and believed to be safer and nontoxic. 




Plants have been used traditionally for their hair colouring, growth promoting and anti-aging properties. Composition of herbal dyes and hair colouring, mordants can be used to deliver a variety of colour to hair. However, substantial improvement is needed in the areas of colour saturation, colour development, initial colour consistency, improved wash fastness, improved hair conditioning without causing hair damage and skin irritation (Naishadham et. al., 2013).

Of all the plants used in this study, Lawsonia inermis (henna, Laali) is the most popular. It is an orange dye commonly used as a deposit - only hair colour whose active component, lawsone, binds to keratin. It is therefore considered semi-permanent to permanent depending on a person's hair type. Henna has been used as a dye for the skin, hair and nails. The usage of red henna has a few reports of allergic contact dermatitis caused by it and/or its active ingredient lawsone (2-hydroxy-1, 4-naphthoquinne, c175480, Natural Orange 6) (Singh, 2014). Type 1 allergy is rare and mainly an occupational hazard in hair dressers (Dias, 2015).

Lonchocarpus cyanescens leaves have been in use as dye for cotton fabric which gives the fabric a blue to blue black colour. There are also reports of its use for production of dyes, stains, inks, tattooes and mordants (Bassey et.al, 2012). The major colouring material in it is indigotin (2, 2-Bis (2, 3-dihydro-3-oxoindolyliden) ( Oduro et. al., 2013). Literature on the use of this dye for hair colouring is sparse .Reports exist on the use of Trema orientalis as a medicinal plant, and lately in pharmaceutics (Adinortey et. al., 2013. There are just mentions of the plant producing brown and black dye, no mention of its use in hair colour.

There are several reports of the use of Pterocarpus osun commonly called black camwood or osun extracts as histological stain for bacteria and mould, collagen (Braide et.al., 2011; Avwioro e.al., 2005). However, it is in the traditional cutaneous adornment by the Yoruba of the southwestern Nigeria that its use have been employed over some centuries (George et. al., 2006). There are however lack of reports of its use in hair colours.

The four plants have been mentioned in literature as dye producing plants but also as medicinal plants with few toxic effects, therefore we have investigated them in this study in attempt to produce hair colours that can colour grey human hair and wool brown to black when combined.

\section{MATERIALS AND METHODS}

\section{Materials}

Chemical reagents used in this study, were all of analytical grade and supplied by the Chemical Store of the Department of Chemistry, of the University of Ibadan, Ibadan, Nigeria. The study Plants Lawsonia inermis, Lonchocarpus cyanescens and Trema orientalis, were obtained from the Botanical Garden of the University. Pterocarpus osun was purchased from Bodija Market, Ibadan, Nigeria. All the plants were authenticated at the herbarium of Botany Department of the University.

\section{Plant Preparation}

The fresh leaves of Lawsonia inermis, Loncocarpus cyanescens, and Trema orientalis were cleaned and air dried. The three plants along with Pterocarpus osun stem were pulverised using a laboratory grinder and stored away until used (Plate 1 - 4). 

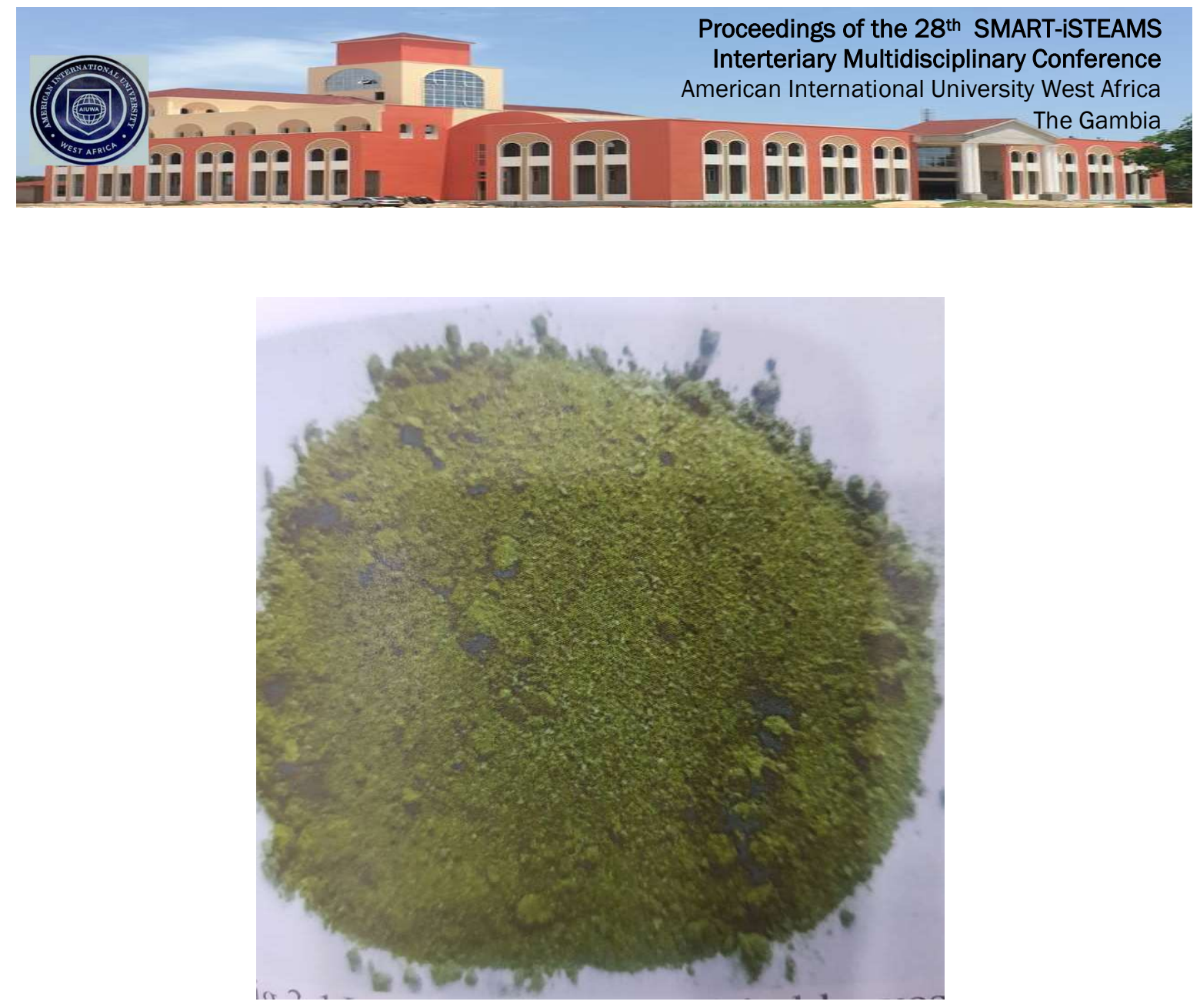

Plate 1: Pulverised Lawsonia inermis Powdered Leaves

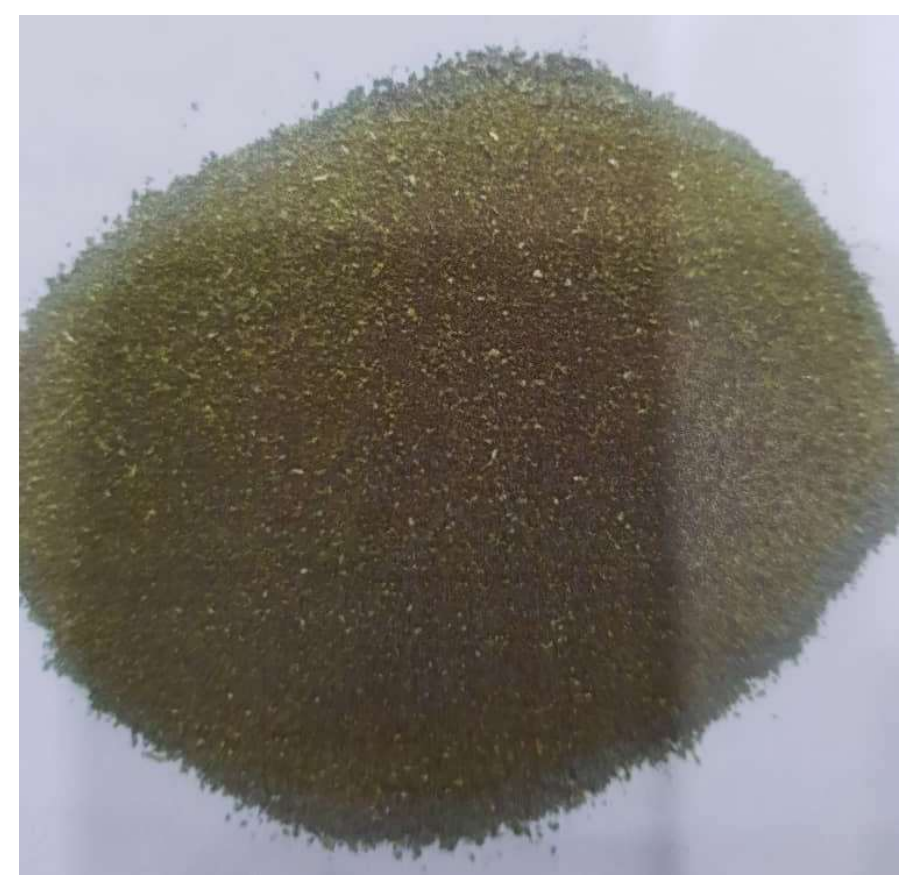

Plate 2: Pulverised Lonchocarpus cyanescens Powdered Leaves 

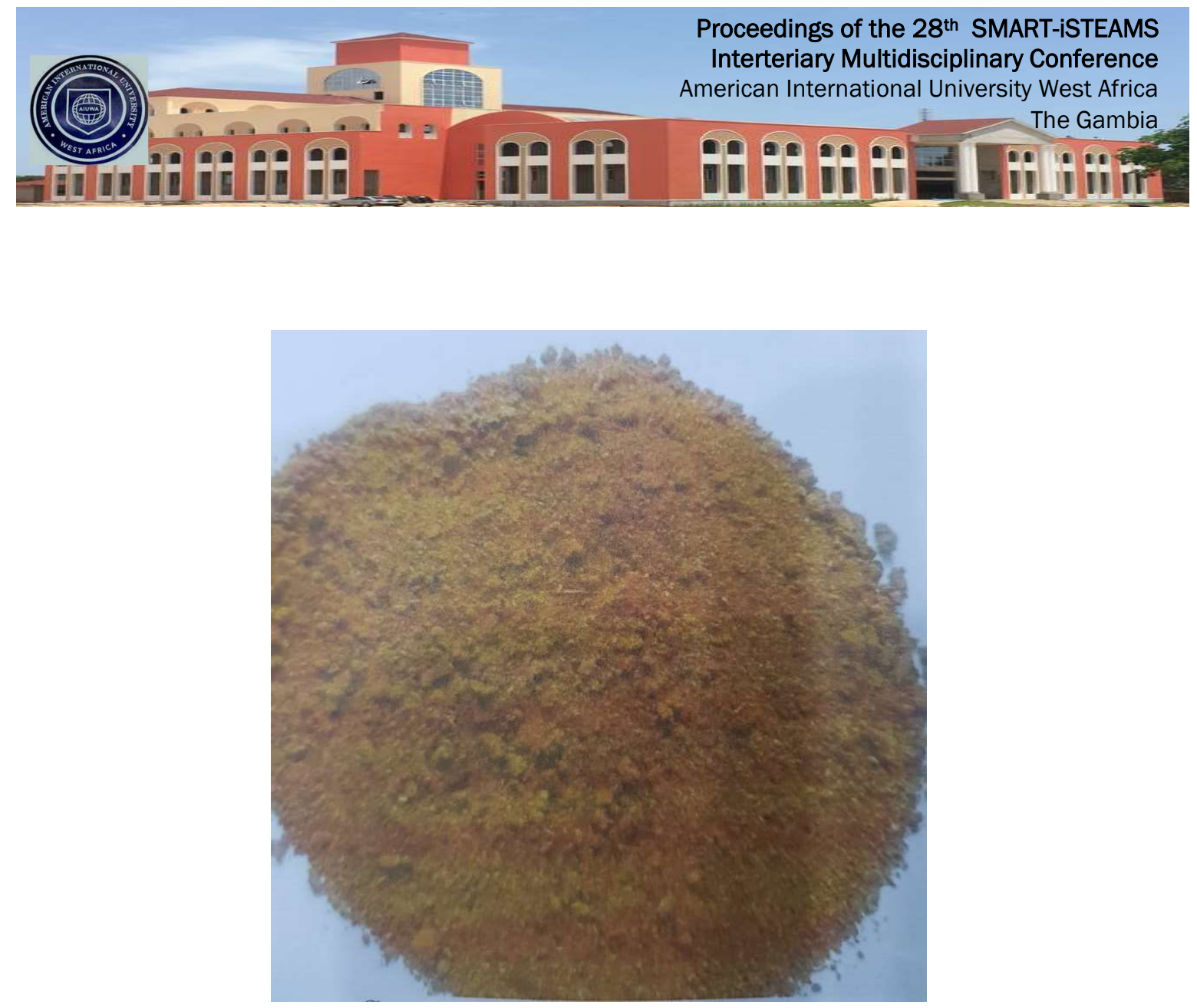

Plate 3: Pulverised Pterocarpus osun Dried Leaves

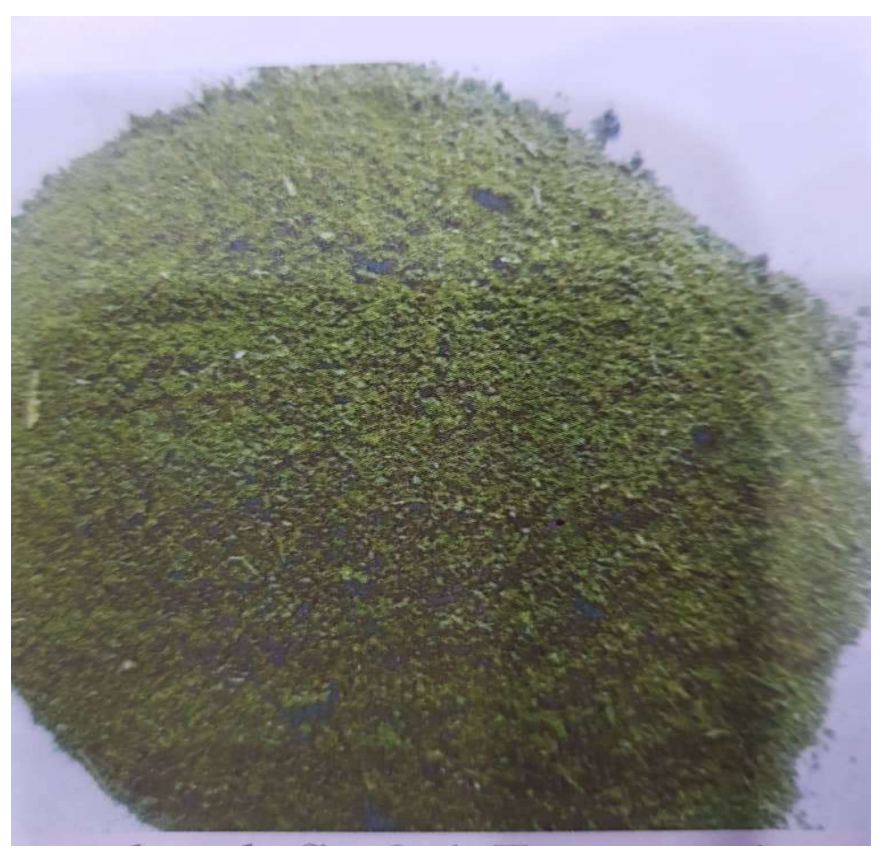

Plate 4: Pulverised Trema orientalis Dried Leaves 




Collection and Preparation of Human Grey Hair and Sheep Wool

The human hair were given as gift by Mrs Akinoye of Oka, Ondo State of Nigeria. Freshly shorn sheep wool was graciously supplied by Dr Olatunji Ajetunmobi and Mrs Funmilayo Ajetunmobi of Oniru Estate, Victoria Island, Lagos, Nigeria. The hair and wool were cleaned with utility water and Petals shampoo several times until they were rid of any dirt. They were then rinsed two times with distilled water. Both were then air dried and stored in clean containers (Plate No 5 and 6).

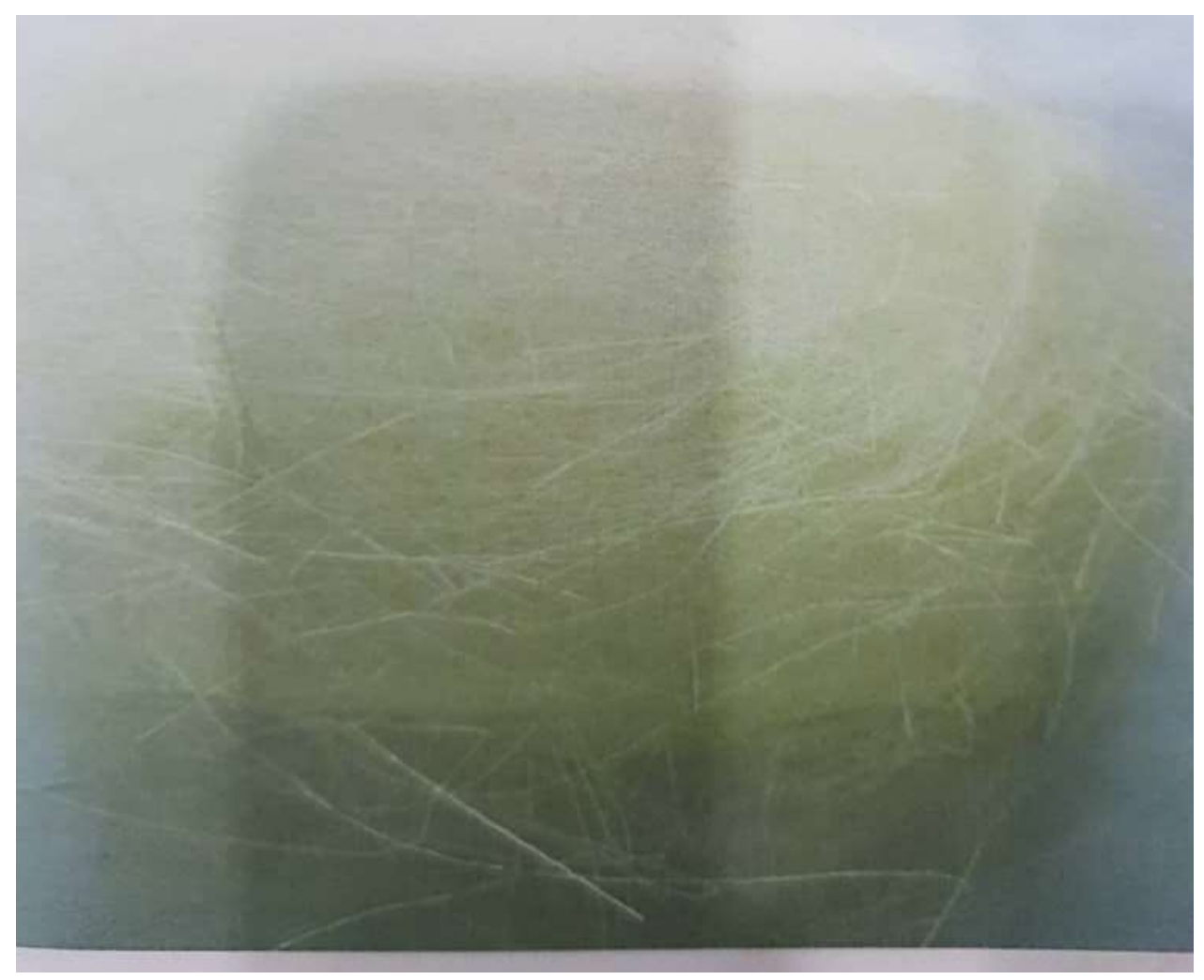

Plate 5: Sheep Wool 

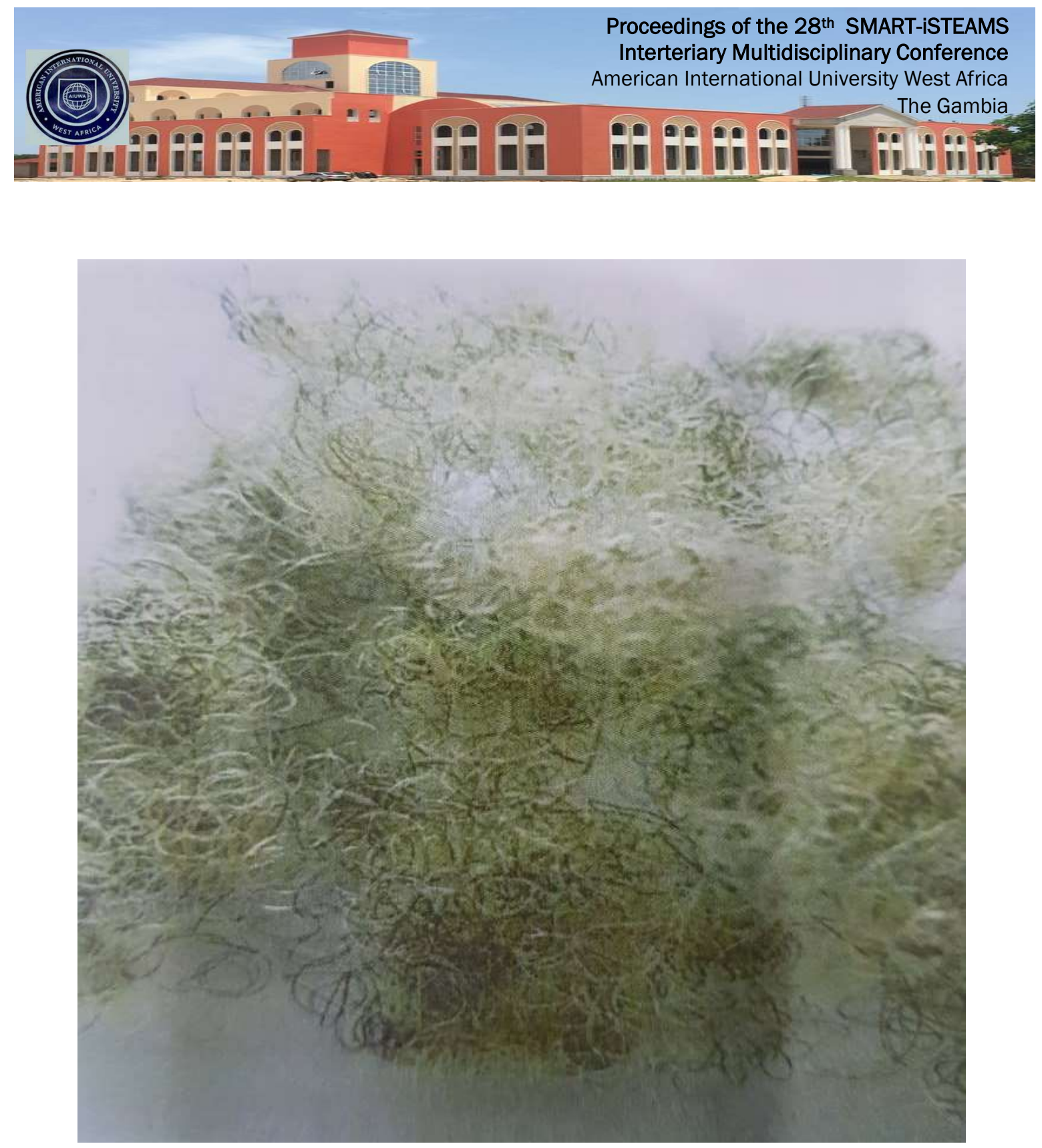

Plate 6: Grey Human Hair

\section{METHODS}

\section{Extraction of Dye from Leaves of Study Plants}

Dye was extracted from the air dried and pulverised leaves and stem of the study plants, following the method of Ezeokonkwo and Okoro, 2012. Some quantity of the air dried Lawsonia inermis was also extracted following the method of Alam et. al., 2007.

\section{Preparation of Hair Colour Formulation}

Seven hair colourants labelled PF-1 - PF- 6 were made by adding the extracted dyes together in ratio 1:1. P-F 1 - 5 contained only four dyes each, while PF-6 contained all the five extracted dyes as shown in the Table below: 




Table 1: Colour Formulary

\begin{tabular}{|c|c|c|l|l|c|c|}
\hline Code & LICE & POEE & & LCEE & TOEE & LIEE \\
\hline PF 1 & 1 & 1 & & 1 & 1 & - \\
\hline PF 2 & 1 & - & & 1 & 1 & 1 \\
\hline PF 3 & 1 & 1 & & - & 1 & 1 \\
\hline PF 4 & 1 & 1 & & 1 & - & 1 \\
\hline PF 5 & 1 & 1 & & 1 & 1 & \\
\hline PF 6 & - & 1 & & 1 & 1 & 1 \\
\hline PF 7 & 1 & 1 & & 1 & 1 & 1 \\
\hline
\end{tabular}

Where LICEE $=$ Lawsonia inermis chloroform extract

LCEE $=$ Lonchocarpus cyanesnces ethanol extract

TOEE $=$ Trema orientalis extract

LIEE $=$ Lawsonia inermis extract

Dyeing of the Human Hair and Sheep Wool

The human hair and sheep wool were cut into small portions. The pieces were then dipped into a formulation and left for two hours. The dye uptake by the samples were observed and recorded.

Colour Fastness at Room Temperature with Increasing Time

The dyed samples of human hair and sheep wool were placed on a white paper and covered with a transparent cellophane sheet and kept for four (4) days at room temperature. The change in colour intensity of the dye was visually observed and recorded by taking photographs of the samples at 2 days intervals.

\section{Effect of Ultraviolet Rays (Sunlight) on Samples of Human Hair and Sheep Wool}

The dyed samples were placed on a white paper and covered with transparent cellophane sheets. The samples were then kept in sunlight for eight (8) hours daily for 4days. The change in the colour fastness of the dyes were observed visually and recorded by taking photographs of the samples at 2days intervals.

\section{RESULTS AND DISCUSSION}

The percentage yields and colours of the dyes extracted from the plants were Lawsonia inermis (1.04 (ethanol); 1.22 (chloroform); orange), Lonchocarpus cyanesnces (1.62; yellow). Trema orientalis (1.40; dark green) and Pterocarpus osun (3.20; dark red)

\section{Dye uptake}

For all samples, colour observed and colour retention power of the samples depended on the percentage of dye in each formulation. Blending of the dyes to produce hair colour formulation resulted in dyes which produce black to brown colouring. This is in agreement with work reported other scientist (Phadatare et. al., 2013). Human hair was observed to retain the dye more effectively than sheep wool for all formulations. The black colouring capacity was maximum with PF - 6; with the order of black colour intensity as PF - $6>P F-3>$ PF - $1>$ P-F 4 $>$ PF- $5>$ PF -2 . This result may be as a result of the synergistic dyeing effect of all the dyes (Plates $7 \& 8$ ). 

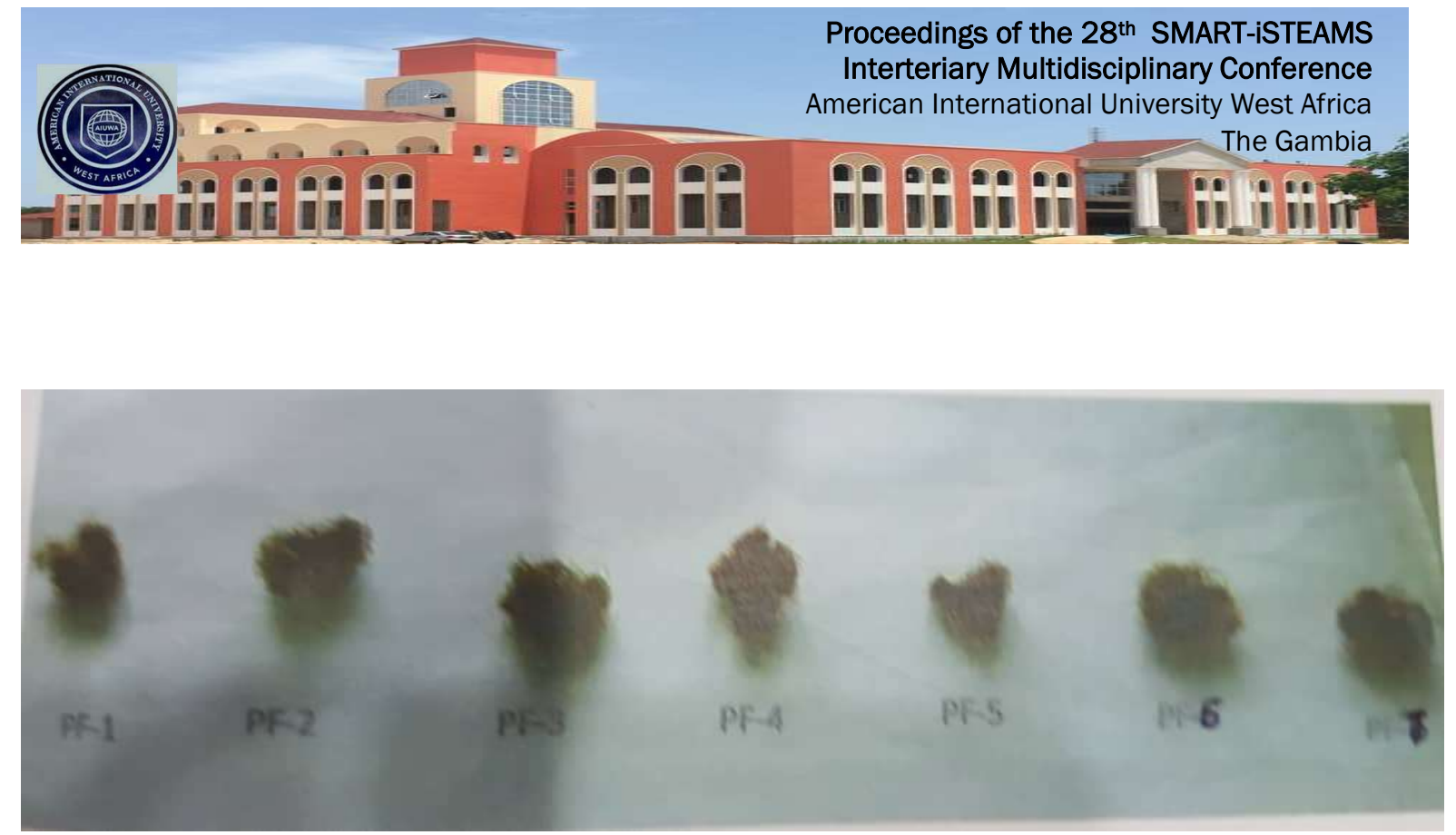

Plate 7: Human Hair Treated with Hair Colour Formulations at Room Temperature on Day Zero

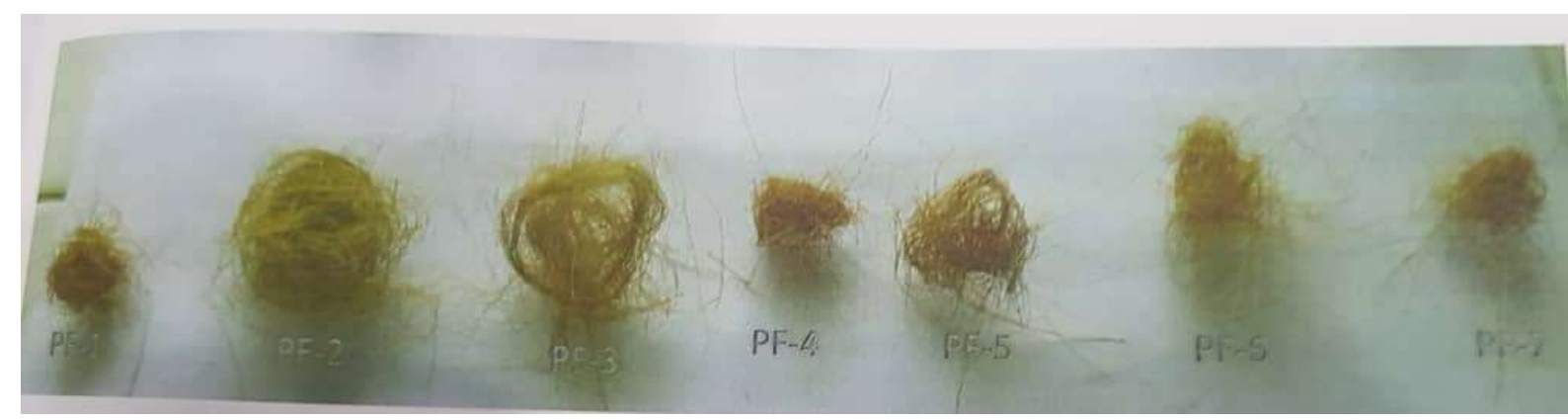

Plate 8: Sheep Wool Treated with Hair Colour Formulations at Room Temperature on Day Zero

Effect Storage at Room Temperature.

It was observed that the depth of the colour appear to increase with increase of stay at room temperature in both human hair and sheep wool (Plate 9 - 12).

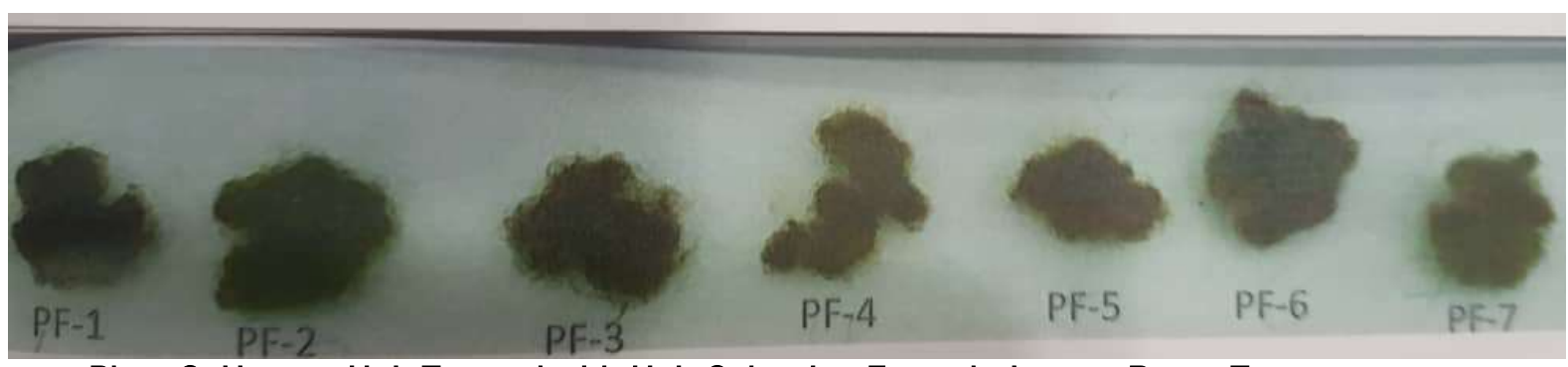

Plate 9: Human Hair Treated with Hair Colouring Formulations at Room Temperature on Day Two 



Plate 10: Human Hair Treated with Hair Colouring Formulations at Room Temperature on Day Four

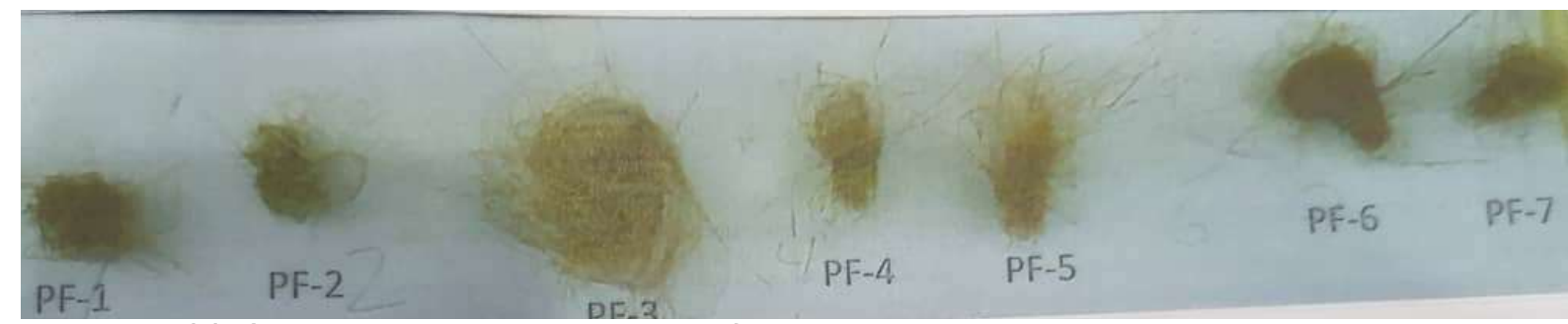

Plate 11: Sheep Wool Treated with Hair Colouring Formulations at Room Temperature on Day 2

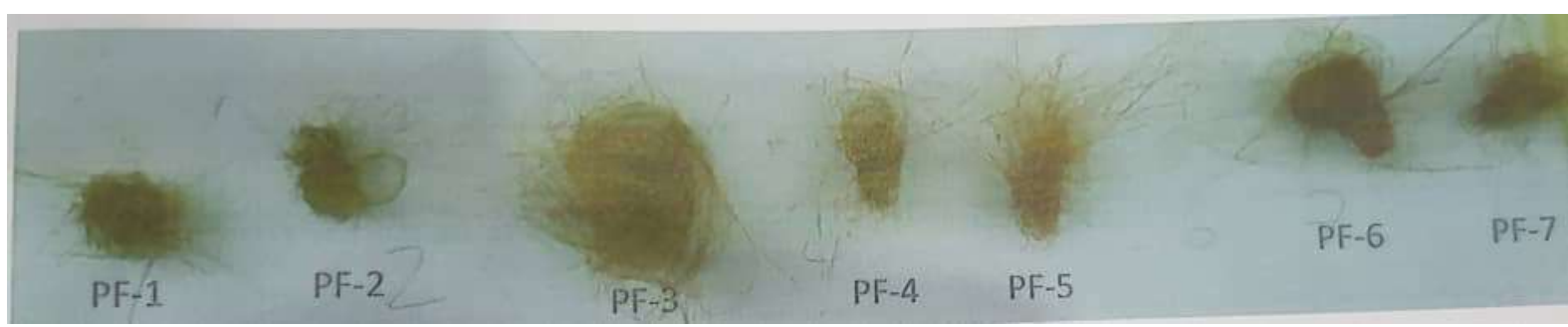

Plate 12: Sheep Wool Treated with Hair Colouring Formulations at Room Temperature on Day 4

Effect of Ultraviolet rays (Sunlight)

The colour of dye on both the human hair and sheep wool faded gradually with increase in time of exposure to sunlight (Plate 10 -12). This is an indication that these vegetable dyes are likely to be temporary to semi - permanent, so they only penetrate into the hair cortex a little at the best (Da Franca et. al., 2015). The colour of the sheep wool appeared to fade faster than that of the human hair. The formulation that contained all the dyes appear to remain adhered to the hair for longer period of time. 

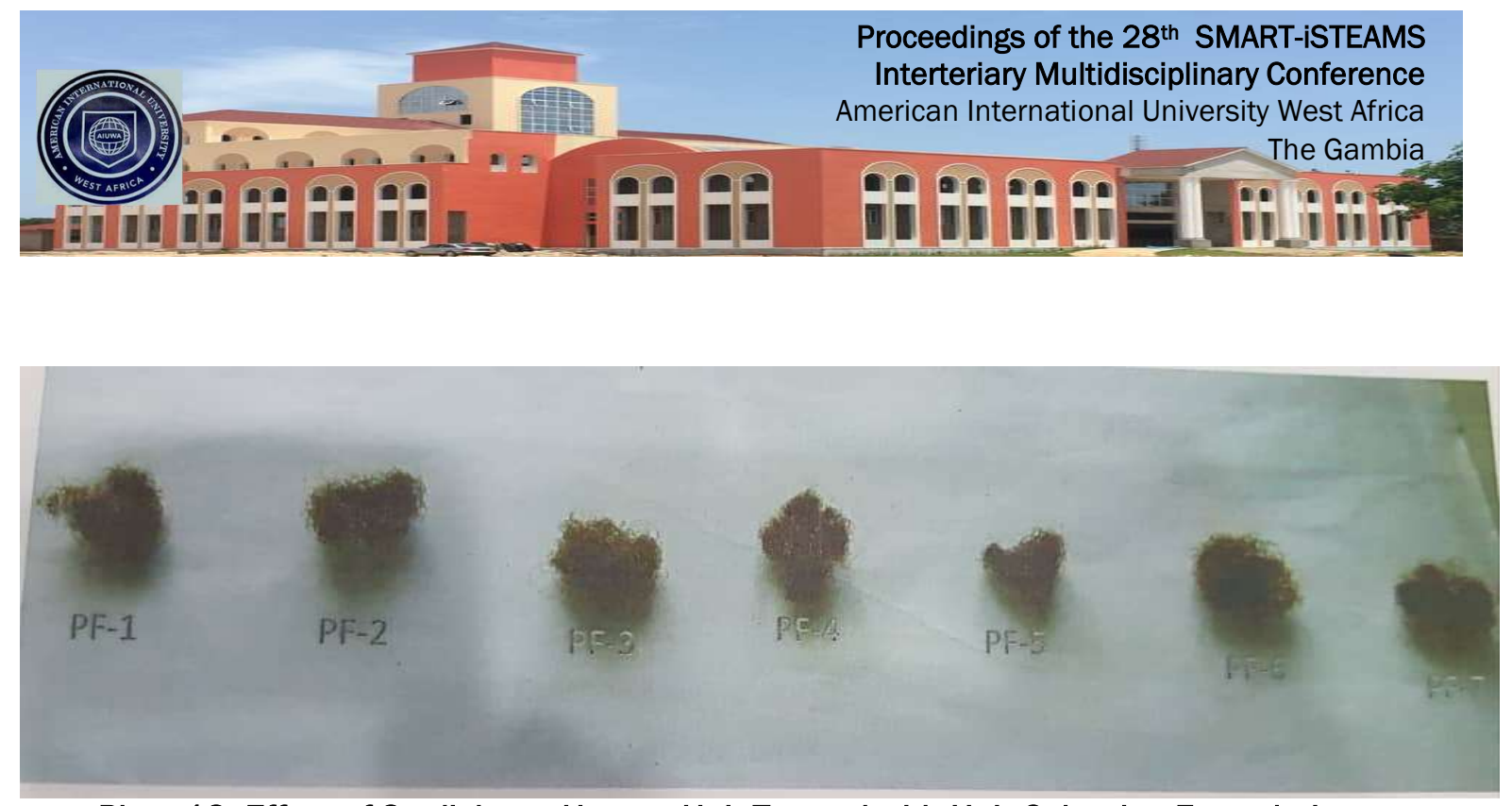

Plate 13: Effect of Sunlight on Human Hair Treated with Hair Colouring Formulations

- Day Zero

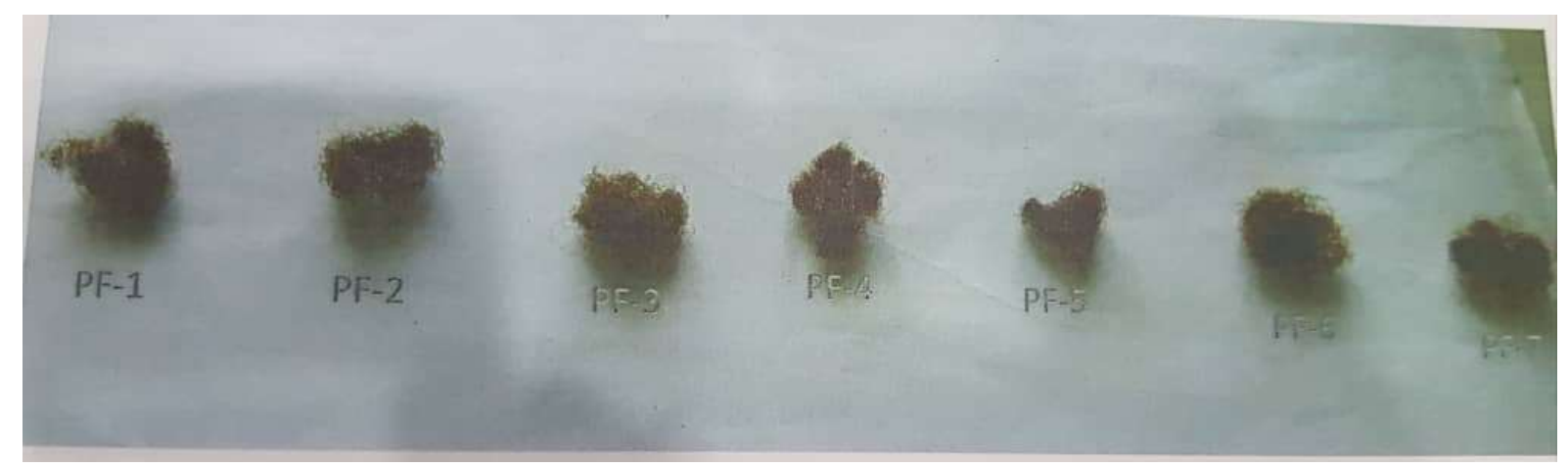

Plate 14: Effect of Sunlight on Human Hair Treated with Hair Colouring Formulations

- Day Two



Plate 15: Effect of Sunlight on Human Hair Treated with Hair Colouring Formulations

- Day Four 

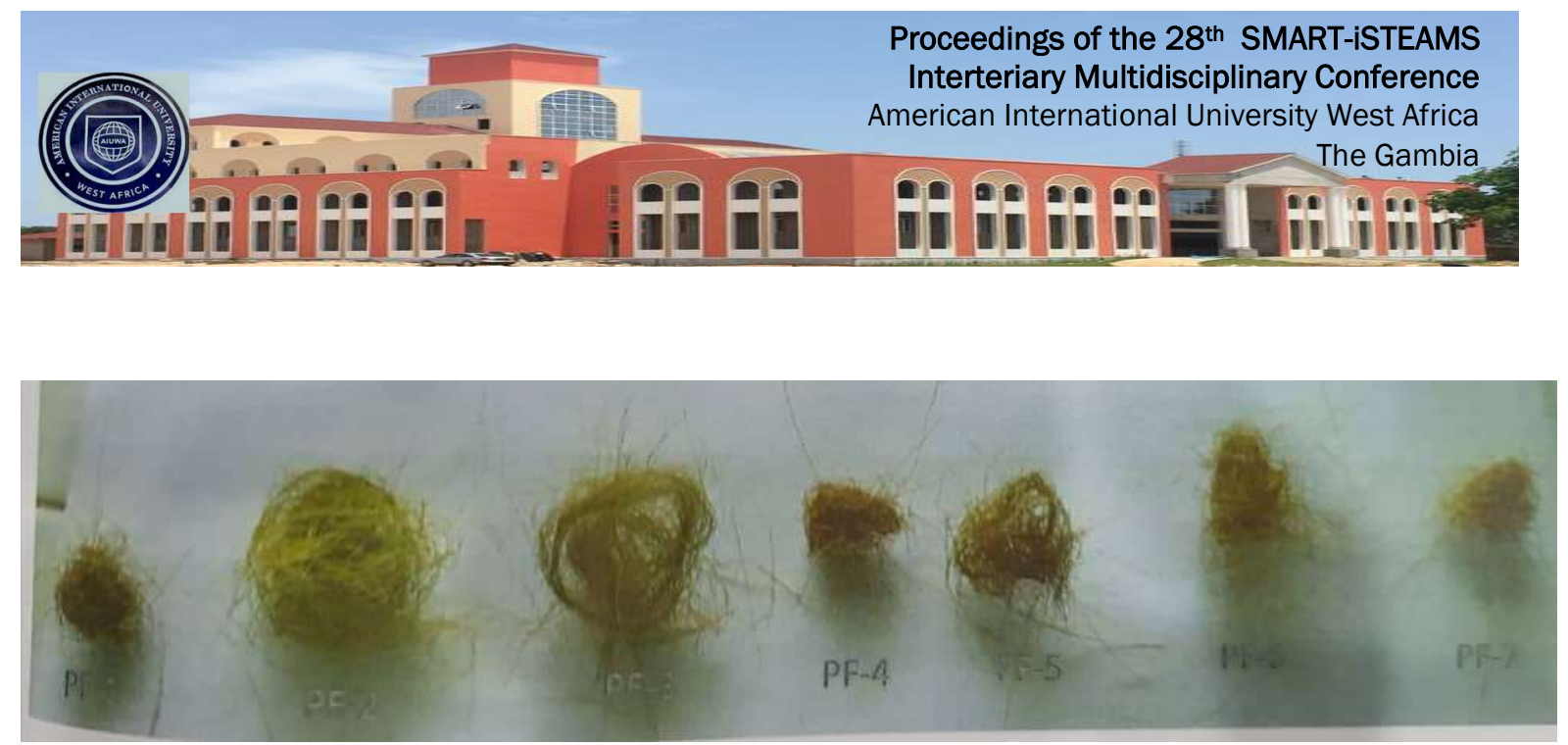

Plate 16: Effect of Sunlight on Sheep Wool Treated with Hair Colouring Formulations -

Day Zero

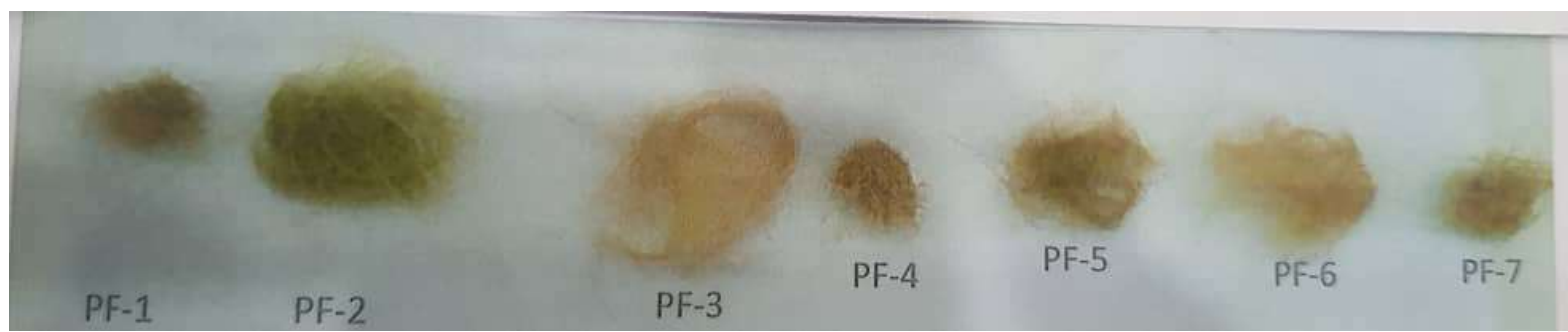

Plate 17: Effect of Sunlight on Sheep Wool Treated with Hair Colouring Formulations

- Day Two

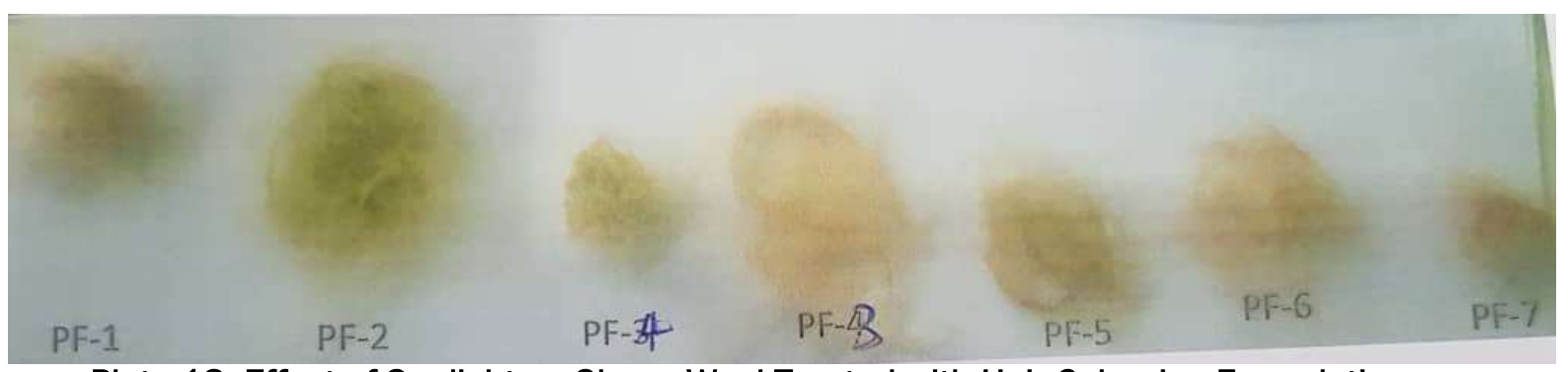

Plate 18: Effect of Sunlight on Sheep Wool Treated with Hair Colouring Formulations

- Day Four

\section{CONCLUSION}

The vegetable dyes extracted from the sample plants appear to have the potential for dyeing human hair rather than Sheep wool which may be used to weave warm clothing. 


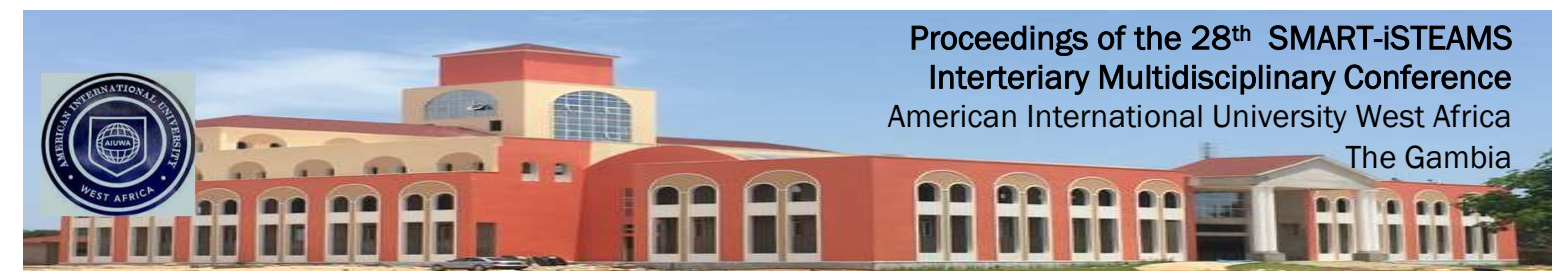

\section{REFERENCES}

1. Zaid, Abdel naser, Ramahi, Rowa., Abu Ghoush A., Jaradat, N. and Musmar, M. 2013 Frequency and Attitudes of Using Hair Dyes among Palestinian Women. International Journal of Pharmacy and Pharmaceutical Sciences: 2 (5) 485 - 488.

2. Adinortey, M. B., Galyuon, I. K. and Asamoah, N. O., 2013 Trema orientalis linn. Blume: A Potential for Prospecting for Drugs for Various Uses. Pharmacognosy Reviews 7 (13): 67-72.

3. Alam, M. M., Rahman, M.L. and Haque, M. Z. 2007. Extraction of Henna Leaf Dye and its Dyeing Effects on Textile Fibre. Bangladesh Journal of Scientific and Industrial Research: 42 (2) 217-222.

4. Avwioro, O. G., Aloamaka, P. C., Ojianya, N. U., Oduola, T and Ekpo, E. O. 2005 Extracts of Pterocarpus osun as a Histological Stain for Collagen Fibres. African Journal of Biotechnology 4 (5) 460-462.

5. Bassey, R. B., Bakare, A. A., Osinubi, A. A. A. and Oremosu, A. A. 2012 Staining Properties of Lonchocarpus Cyanescences on the Testes Open Access Scientific Reports 1: 211

6. Braide, W., Akobundu, C., Nwaoguikpe, R. N.., and Njiribaeko, L. C. 2011 The Use of Extracts from Four Local Nigerian Plants for Staining of Selected Bacteria and Moulds. African Journal of Microbiology Research Volume 5 (1) 79-86.

7. Boga, C., Delpivo, C., Ballarin, B., Morigi, M.,Galli, S., Micheletti, G., and Tozzi, S. 2013. Investigation on the dyeing Power of Some Organic Natural Compounds for a Green Approach to Hair Dyeing. Dyes and Pigments Journal: 97(1) 9-18.

8. Booth, G., Zollinger, H., McLaren, K., Sharples, W. G. and Westwell, A. 2000. Dyes, General Survey. In Ulmann 's Encyclopedia of Industrial Chemistry Wiley -VCH.

9. Corbest, J. F. 1998. Cosmetic Science Monographs: Hair Colorants - Chemistry and Toxicology No 2 - Cosmetic Science Monographs No 2 Series Editor Hilda Butler, Michelle Press

10. Da Franca, S. A., Dairo, M. F., Esteves, V. B., Baby, A. R., Velasco, M. V. R. 2015 Types of Hair Dye and Their Mechanisms of Action Cosmetics 2 (2) 110-126.

11. Ezeokonkwo, M. A. and Okoro, U. C. 2012. New Dyes for Petroleum Products. Journal of Emerging Trends in Engineering and Applied Sciences: (JETEAS) 3(1): 8-11.

12. Dais, M. F. R. G. 2015 Hair Cosmetics: An Overview .International Journal of Trichology 7(1): 2-15.

13. Gera, R., Mokbel, R., Igor, I and Mokbel, K. 2018 Does the Use of Hair Dyes Increase the Risk of Developing Breast Cancer? A Meta-analysis and Review of the Literature. Anticancer Research 38 (2) 707-716

14. Harrision, S., and Sinclair, R. 2003. Hair Colouring, Permanent Styling and Hair Structure. Journal of Cosmetic Dermatology: 2 (3-4) 180-185.

15. Kvavadze, E., Bar-Yosef, O., Belfer-Cohen, A., Boaretto, E., Jakeli, N.,Matskevich, Z. and Meshveliani, T. 2009. “30,000-Year-Old Wild Flax Fibers”. Science: 325 (5946): 1359.

16. Oduro, W. O. and Addo-Yobbo, F. 2013 Enhancing the Value of Indigo-Blue Des from Lonchocarpus Cyanescens Leaves. International Journal of Applied Science and Technology 3 (5)78-86

17. Naishadham, P., Sushma, P. R., Dasika, R., D., and Tangirala, S. 2013 Evaluation of Organic Hair Dye Formulation by an Environment Friendly Process. International Journal of Pharmaceutical Sciences Review and Research: 21 (2) 152-157. 


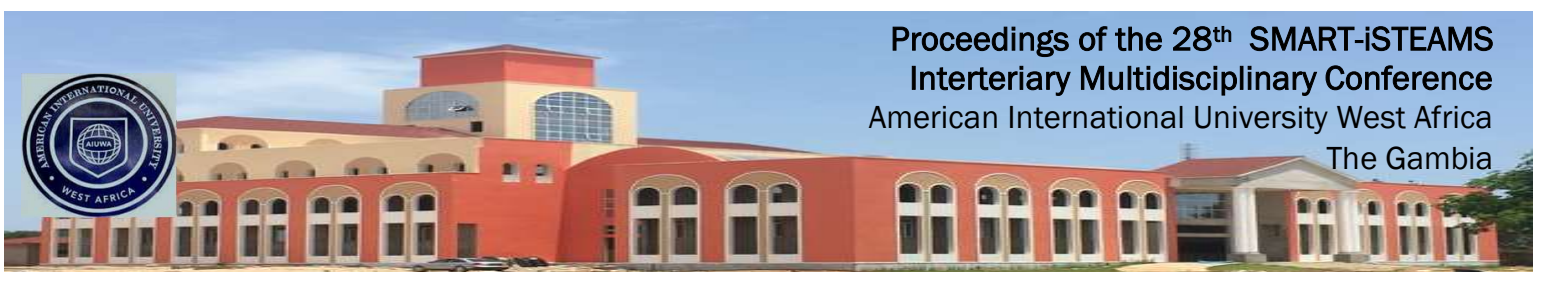

18. Phadatare, S. P., Nesari, T N., Pokharkar, D., Pingle, R. P. and Gadje, M. S. 2013 Comparative Study of Dyeing Efficiency and Retention Capacity of herbal hair Dyes. International Journal of Research in Ayurveda and Pharmacy 4 (2): 198 -202.

19. Shahi, Z., Mehrizi, M. K.,Hadizadeh, M. 2017. A Review of the Natural resources Used to Hair Colour and Hair Care Products. Journal of Pharmaceutical Sciences and Research 9 (7): 1026 - 1030.

20. Sharma, P.P. 2008 Hair Structure: In Sharma P.P. Edited. Cosmetics Formulation, Manufacturing and Quality Control, $4^{\text {th }}$ ed. Vandana Publications Pvt Ltd. Delhi.

21. Singh, K. D. and Lugman, S 2014 Lawsonia inermis (L): A Perspective on Anticancer Potential of Mehndi/Henna Biomedical Research and Theraphy 118 (2014)

22. Zoolinger, H. 2003. Colour Chemistry, Synthesis, Properties and Applications of Organic Dyes and Pigments, $3^{\text {rd }}$ edition. Weinheim. Wiley-VCH. 